\title{
Models of Educational Management and the Implementation of Change: A Case Study
}

\author{
Hassan Qutub \\ English Language Institute, King Abdulaziz University \\ Jeddah, Saudi Arabia
}

Received: July 25, 2021 Accepted: August 20, 2021 Published: August 23, 2021

doi:10.5296/ijele.v9i2.18958 URL: https://doi.org/10.5296/ijele.v9i2.18958

\begin{abstract}
The current paper reported on a case study of the implications of change implemented by a Saudi Arabian public university located in an urban setting. The university implemented a change in the process of preparing students to study in English as a medium of instruction in scientific departments, which required establishing an English Language Center (ELC) within the University. Bush's models of management and leadership (2020) were applied to analyze the case from a leadership perspective. Results indicated that the formal model was the most dominant followed by the subjective, cultural, collegial, and Political models. Although the nature of the institution and its cultural context demonstrated certain formal and cultural features, the author argues that it is possible to implement more collegial practices.
\end{abstract}

Keywords: educational management, change management, management models 


\section{Introduction}

Education is at the heart of the development of any nation in our world. The provision of education lends itself to the cultural as well as the political components of the society in which it exists (Foskett \& Lumby, 2003; Bush, 2019). These cultural and political components are usually prone to change from time to time, which makes change an inevitable practice in educational institutions. However, change in educational institutions cannot be successfully implemented without proper educational leadership.

Change has been defined "as a dynamic and continuous process of development and growth that involves reorganization in response to felt needs" (Morrison, 1998: 13). From the above definition, it is evident that the major incentives behind change are attributed to development in the light of felt needs; however, development in education is a vague term that can accommodate an endless number of possibilities.

Researchers within the educational leadership field have made several efforts to capture and describe the process in which change is implemented. Bush (2020) developed a framework for educational change in which he identified six different models including formal, collegial, political, subjective, ambiguity, and cultural models. The process of implementing change can be described through any combination of the above models depending on the context of the educational institution and the nature of change to be implemented. Several studies have described the implementation of change in specific educational contexts. For example, Baki (2004) examined how the gender-segregated higher education in Saudi Arabia is functioning to meet the requirements that the country has to fulfill in order to be an effective participant in the global economy. She found out that the higher educational system of Saudi Arabia is placing a heavy burden on the national economy through (1) putting several restrictions on women's access to the labor market through limiting the academic fields that women can obtain a degree on (e.g., some engineering degree programs are not available for women) (2) the higher education system failed to prepare men to the realities of the Saudi labor market, which is changing rapidly to meet the challenges of a global knowledge-based economy. This led to unemployment for Saudi citizens, and an over use of the foreign expertise to fill in the positions that Saudis were not adequately prepared for. She suggested that the cultural conservatism and its effects on the educational system should be revisited.

The above study illustrates the complex nature of change and how the context in which the change is implemented can alter the way leaders deal with, and understand change. Therefore, the current study attempts to investigate the implementation process of an educational change in a Saudi Arabian context in which a Saudi public university adapts a different approach for preparing students to study in English as a medium of instruction in scientific departments. This investigation will be guided by Bush's (2020) framework. In the remainder of the paper, the author will present the case and the implantation of the change, followed by a brief account of Bush's (2020) framework, and then the author will apply the framework to the case of educational change. Finally, a critique of the application of Bush's (2020) framework to the case of the university under investigation will be presented. 


\section{The Case of the University under Investigation}

The Saudi Arabian education system gives direct attention to teaching Arabic language and Islamic studies from elementary to tertiary education (Prokop, 2003). This attention to Arabic, especially in tertiary education, has led to limited attention to the teaching of the English language. As a result, the English language proficiency level of students at Saudi universities became relatively low (Javid, Al-thubaiti, \& Uthman, 2012). This has affected the quality of education in Saudi universities, because all of the scientific departments (e.g., engineering \& medicine) required their students to study in English, due to the very limited availability of materials written in Arabic in the scientific fields. In the past, universities - including the university under investigation - used to have English for Specific Purposes (ESP) programs in which students were enrolled before joining the scientific departments, in order to polish their English language kills, and to provide them with the basic terminology that are required to understand English texts written in their respective academic fields. However, because the proficiency level of the students joining the university was very low, the ESP programs were not sufficient to prepare students to use English as a language of instruction. As a result, faculty members used to shift between Arabic and English, which caused confusion on the part of the students. Moreover, the majority of the students found the textbooks overwhelming because of the big gap between the language used in the textbooks and the students' actual proficiency levels.

The Saudi government has invested billions of Riyals on higher education and passed on policies that require the development of the higher education system in order to harvest better outcomes that can help Saudi Arabia in coping with the knowledge-based global economy (Baki, 2004), and to meet the requirements of the Saudi Vision 2030. Some of these policies required Saudi universities to provide quality education and to equip their students with $21^{\text {st }}$ century skills in order to enable them to fit themselves into the job market and to increase the number of jobs filled in by Saudis and decrease the number of jobs filled in by foreigners. This is represented by the Human Capability Development Program which is one of the major programs composing the Saudi Vision 2030 (Vision 2030)

As a response to the internal pressures of students' low proficiency levels and the external pressers of the government to provide a better education in line with Vision 2030, the university under investigation decided to start a foundation year program in which all new university students are enrolled. The foundation year program aims at bridging the gap between the students' academic achievement from the secondary education and the academic level required for university studies. It also allows student to choose between science or arts tracks. Both tracks take the same English language intensive course (i.e., 18 hours per-week); however, they also take four other courses in different academic fields depending on their track (i.e., science or arts) each of which is presented in three hours per-week.

To put this into action, the university was required to establish a new center; therefore, the English Language Center (ELC) was established. This required providing university buildings that can house offices for administrators and teachers as well as classrooms for students. More importantly, it required providing a team of experienced administrators and 
teachers who can help the university to reach its goal behind establishing the ELC. After one year of preparation, the university was able to start the program, which went through different stages of development itself. Now, the English language program requires students to take a placement test, which uses the Common European Framework of Reference for Languages (CEFR) to divide students into four proficiency levels ranging from true beginners to lower intermediate. Students' evaluation is done though a portfolio that students build throughout each course, a midterm, and a final exam. The midterm and final exams are achievement tests designed by the testing unit based on the textbooks taught for each level.

The structure of the ELC is a clear hierarchy. The President and the Vice-Presidents of the center are appointed by the president of the university. A number of units branch from each Vice-Presidency within the ELC. Unit heads are appointed by the President of the ELC. Teacher evaluation and professional development is conducted by a number of experienced teachers with high teaching performance. Each one of these teachers is given a low teaching load, and is called a coordinator. The work of coordinators is evaluated by a smaller group of senior coordinators. Senior coordinators, in turn, are evaluated by the Vice-President for Academic Affairs.

\section{Educational Leadership Framework}

Different efforts have been made to describe the different models of educational management (Bush, 2020; Fullan, 2001). The author has chosen the framework suggested by Bush (2020) because he has assumed that it can capture most of the aspect represented in the case of the university under investigation. Tony Bush's first attempt to identify models of educational management was on his book, which was published in 1986. His framework included only five models of educational management including formal, collegial, political, subjective, and ambiguity models (Bush, 1986). The framework was refined and an additional group featuring cultural models was added. Now, the framework is comprised of six groups of models each of which share a number of common features. Below is a brief presentation for each of these models:

\subsection{Formal Models}

Several approaches fall under the umbrella of formal models. These approaches emphasize the structural elements of an institution and focus on achieving institutional objectives using rational thinking (Bush, 2020). Formal models can be defined as the group of models which view organizations as "hierarchal systems in which managers use rational means to pursue agreed goals. Heads and principals possess authority legitimatized by their formal positions within the organization and are accountable to sponsoring bodies for the activities of their institution" (Bush, 2020:33). Several models can be categorized under the formal model including the structural, systems, bureaucratic, rational, and hierarchal models (Bush. 2020).

\subsection{Collegial Models}

This group of models claims that power and decision-making should be distributed among 
the members of an institution (Bush, 2020). By definition, the assumption underlying collegial models claims that an ideal organization is the one that is able to "determine policy and make decisions through a process of decision leading to consensus. Power is shared among some or all the members of the organization who are thought to have a shared understanding about the aim of the institution" (Bush, 2020:59). Recently, there has been a growing interest in distributed leadership, which share some characteristics with the collegial model (Bolden, 2011; Harris, 2007, 2008; Jones, Lefoe, Harvey, \& Ryland, 2012). Distributed leadership can take several forms, which involve different levels of distribution within educational institutions (MacBeath, 2009). This variation in the levels of distribution makes distributed leadership an ambiguous endeavor that requires real distribution of power and shared decision-making. Therefore, the leader who only takes account of the views of his/her staff without giving them the power to reach consensus in the decision-making process is not implementing a distributed leadership approach (Bush, 2020).

\subsection{Political Models}

Political models assume that bargaining and negotiation are at the heart of the decision-making process (Bush, 2020). In political models "interest groups develop and form alliances in pursuit of a particular policy objective. Conflict is viewed as a natural phenomenon and power accrues to dominate coalitions rather than being the preserve of formal leaders" (Bush, 2020:87).

\subsection{Subjective Models}

Subjective models focus on individuals and claim that an organization is the sum of its individuals (Bush, 2020). According to subjective models, "participants are thought to interpret situations in different ways and these individual perceptions are derived from their background and values. Organizations have different meanings for each of their members and exist only in the experience of those members" (Bush, 2020:109).

\subsection{Ambiguity Models}

The assumption underlying ambiguity models is that uncertainty and unpredictability are the basic characteristics of decision-making in an organization (Bush, 2020). According to ambiguity models, "there is no clarity over the objectives of institutions and their processes are not properly understood. Participation in policy making is fluid as members opt in or out of decision opportunities" (Bush, 2020:127).

\subsection{Cultural Models}

Cultural models stress the importance of the unstated cultural norms, values, and beliefs that are usually taken for granted by the members of an institution, and how these values can affect their behaviors and institutional decisions (Bush, 2020; Hallinger \& Leithwood, 1996). Moral leadership can be affiliated with cultural models. The underlying assumption of moral leadership is that the personal values and beliefs of the leader can directly impact his/her decision-making within the educational institution (Leithwood, Jantzi, \& Steinbach, 1999). 


\section{Applying Bush's (2020) Framework to the Case of the University under Investigation}

The case of the university under investigation illustrates several management models from Bush's (2020) framework. Formal models are represented in the organizational hierarchy of the English Language Center (ELC) and the university as a whole, which imposes a high level of accountability towards individuals on the top of that hierarchy. This makes the university as well as the ELC operate as a system in which the different units are linked in a hierarchy. The goals of the ELC are derived from the university's goals. The President and Vice-Presidents of the ELC work with the staff members towards achieving the preset goals. Therefore, the decisions are made on the bases of the institutional goals. The relationship between the governing body of the ELC and the teachers and other staff members is based on positional power. Managing teachers and students in the center represented a challenge to the leaders of the ELC, which resulted in applying several managerial practices to ensure that every staff member is doing his/her job properly. For example, the content for each of the four levels in the ELC was divided on the 18 hours of English language teaching and put into a chart that states what teachers should be doing in each hour every week (e.g., hour No. 1: teach pages 3-5 from the textbook). This is to ensure that all teachers cover the required material before each assessment (i.e., midterm and final exams).

Despite all the formal leadership features that categorize the case of the university under investigation, some collegial aspects can still be observed. Even though the decision-making process is guided by the preset and agreed upon goals of the institution, there is still some room for distributed leadership within the ELC. This distributed leadership does not empower all of the staff members; instead, it gives a limited amount of power to the first two levels of the hierarchy that immediately follow the President of the ELC, which include the Vice-Presidents and the unit heads. This group conducts regular meetings to discuss certain internal decisions, and usually the decision is made based on agreement among the members. For example, the ELC moved from a two-semester system of teaching to a quarter system. This major decision and its implementation plan were discussed intensively in the meetings before it was agreed upon, and finally implemented. However, this is not always the case. Some decisions are dictated by the university president or the President of the ELC and are implemented without any negotiation. This shows that the collegial aspects illustrated in the case of the university under investigation are limited and only implemented within the higher levels of the hierarchy.

The case of the university under investigation illustrates very limited aspects of the political model. The goals of the ELC are taken for granted by the staff members; therefore, no conflict exists over the goals. This also shows that the goals are stable and not negotiated among the members of the institution. Power comes from the individual's position within the hierarchy rather than from bargaining and negotiation. However, some of the decisions are based on bargaining; for example, when it comes to convincing specific individuals to take certain roles within the institution, the leaders of the ELC might bargain either by offering additional incentives, or by reducing the required teaching load of a staff member depending on the difficulty of the role to be fulfilled. This shows that a very limited political stance is illustrated in the case of the university under investigation. 
The representation of the subjective model is vey clear in the case of the university under investigation. Since the individual's position in the organizational hierarchy dictates the amount of power that he/she has within the ELC, certain decisions that are taken by the President clearly exemplify his personal touch. A number of projects and initiatives were started based on the personal and subjective preference of the President (the first leadership level at the ELC) without involving the second or the third leadership levels in the decision-making process.

The ambiguity model is not characterized in the case of the university under investigation. There is no lack of clarity in the goals of the institution, or the roles of the different individuals are clear. The decisions are planned and geared towards achieving the institutional goals. There is a strong centralization of power in the upper levels of the institutional hierarchy. The relationships between the different units within the ELC are very clear and systematic in nature. The relationship between the ELC and other external bodies is very limited, as the policy of the ELC comes from the top management of the university (i.e., the president and vice-presidents). This means that ELC leaders are accountable to the top management of the university and not to any other external body.

The cultural model within the case of the university under investigation is manifested in the Saudi Arabian cultural tradition, which is in itself a manifestation of the Islamic religion. Physical representations of the Islamic culture, even when not stated in the institutional policy, are illustrated in many decisions taken by the university as well as the ELCI's administration. For example, because women are segregated from men in most of the aspect of life in Saudi Arabia, meetings between the male and female administrators take place through a closed TV circuit where females can see and hear males; however, males can only hear, but not see females. The domination in leadership positions within the ELC, like any other organization in Saudi Arabia, is for males. This means that the President can only be a male, and in the female section the head person is always a Vice-President. Other Islamic cultural manifestations include giving students and employees a break from classes or office work during prayer times and giving staff and students vacations during Islamic religious occasions.

\section{Critiquing the Case of the University under Investigation and its Application of the Management Models}

The case of the university under investigation is mostly affected by the formal management model. This model was over used in many different ways. To begin with, the decision to start the foundation program at the university came from two sources of pressure, which included the internal need represented in low general academic level of new university students and especially the low proficiency level in the English language as well as the government's pressure towards a more globalized education in line with the Saudi Vision 2030. However, the university decided to start the program without consulting the students, even though that decision would result in a direct impact on their academic lives (i.e., this decision added one more year to the usual timeframe required to obtain a bachelor's degree). The decision was 
partly collegial, as it was only discussed among the president of the university and his vice-presidents. After they made the decision, others just needed to comply with it. Even though collegiality is represented among the higher levels of the institutional hierarchy, it is only limited to a number of decisions. Moreover, even when the top management members meet to agree on a specific decision, the final decision is still on the hands of the top leader who can take an individualized decision regardless to what the top management members agree upon. This shows a vague line between restricted collegiality and a top-down formal approach in the decision-making process with more bias in favor of the formal approach. For example, the President of the ELC took several decisions concerning increasing the working hours (e.g., some tests were scheduled during weekends) without involving any of the staff in those decisions. Although teachers as well as some of the Vice-Presidents were unsatisfied with that decision, they had to comply with it. The example above illustrates not only the formal top-down stance in educational leadership, but also the subjective stance. Individual decision-making allows for the individual characteristics of the leader to affect the decisions taken. In the example above, increasing the working hours is an individual decision, which is affected by the background of the President of ELC who worked previously for a number of companies that work for longer hours (i.e., including working during weekends) compared to educational institutions. In addition, the above example can illustrate the contradiction between the formal and the collegial approaches to educational leadership. That is, the more formal the decision-making process is, the less collegial it becomes. It also illustrates how the subjective approach can be associated with the formal approach to educational leadership, and that these two approaches can sometimes bring disadvantages to the institution, as personal decisions can make others within the institution feel excluded form the decision making process. Another disadvantage is that formal and subjective approaches can limit the creativity and motivation of the staff, as their role becomes only limited to obeying the orders of the head leader.

The cultural model is illustrated in several aspects in the decisions taken by the ELC's leaders. The most obvious example is the unequal distribution of power between the male and female sections. It goes without saying that the President of the ELC - like any other entity within the university - is a male. In the female section, the head leader is always a Vice-President. This means that there is a cultural bias in power distribution in favor of the male section. This cultural rule is not stated in any document within the institution; however, it cannot be violated. This observation is supported by the findings of Baki (2004), who called for the need to revise the cultural conservatism and its effect on the Saudi educational system. However, in Saudi Arabian government educational institutions, even though unstated cultural rules might be negative or lead to disadvantages (e.g., there might be a more qualified person to hold the position of the President from the female section), breaking them is often impossible. Attempts to violate such cultural rules will often be stopped by several authorities both inside and outside the educational institution.

Ideally, no management model can be perfect for every situation (Bush, 2020). Although the nature of the situation at the university under investigation as a government institution dictates some formal aspects of management, there is still more room for more collegiality. 


\section{Ml Macrothink}

International Journal of English Language Education

ISSN 2325-0887

2021, Vol. 9, No. 2

The teaching staff members should be more involved in the decision-making process. This can be achieved through:

1- Conducting annual meetings with the teaching staff, in which decisions can be negotiated before their application.

2- Allowing teachers have more freedom inside the classroom instead of dictating what they should teach in every class. This will allow teachers to be more creative.

3- Refraining from subjective decisions that originate from the personal experiences of the leaders and reassessing the decisions as a team before they are applied.

4- Conducting online surveys to measure teachers' as well as students' satisfaction levels with the different decisions taken.

With the teachers' experiences and knowledge about the needs of the students within the institution, they will provide leaders with valuable information that can guide the decision-making process. Moreover, teachers will be more motivated, as they will feel included in the decision-making process within their institution.

\section{Conclusion}

This paper presents a change implemented by a Saudi Arabian public university located in an urban setting, which started a foundation year program to elevate students' English language proficiency levels. As a result, the university will be able to make English the medium of instruction in scientific departments. The case of the university under investigation illustrates the management models presented by Bush (2020) with different levels. The formal model is the clearest on the surface, as it illustrates most of the practices within the institution. The high level of formal management led to more individual decisions, which led to a subjective stance. Collegial models are represented but are very limited as they only take place among the members occupying the top levels of the institutional hierarchy. Even though some of the above features are difficult to change, as they were dictated by the nature of the institution and its cultural context, more collegiality in the decision-making process could evidently lead to more positive outcomes. The university under investigation and the ELC should consider allowing an interval of time before taking key decisions, during which staff members are given the chance to participate effectively in making different decisions, which leads to a more collegial and less formal and subjective leadership approach. Finally, even though it is difficult to change the cultural norms within the ELC, the university under investigation should distribute the leadership power equally between male and female sections through giving male and female leaders an equal amount of power. This way, male and female leaders will work together towards achieving a more balanced and collegial decision-making process. 


\section{References}

Baki, R. (2004). Gender-segregated Education in Saudi Arabia: Its Impact on Social Norms the Saudi Labor Market. Education Policy Analysis Archives, 12, 28. https://doi.org/10.14507/epaa.v12n28.2004.

Bolden, R. (2011). Distributed Leadership in Organizations: A Review of Theory and Research. International Journal of Management Reviews, 13(3), 251-269. https://doi.org/10.1111/j.1468-2370.2011.00306.x.

Bush, T. (1986). Theories of educational management. London: Harper \& Row Publishers.

Bush, T. (2020). Theories of educational leadership and management (5th ed.). London: SAGE. ISBN 978-1-5264-3212-4. [Kindle DX version]. Retrieved from Amazon.com.

Bush, T. (2019). Models of educational leadership. In T. Bush, L. Bell, \& D. Middlewood (Eds.), Principles of educational leadership \& management. Sage.

Foskett, N., \& Lumby, J. (2003). Leading and managing education international dimensions. London: P. Chapman Pub. https://doi.org/10.4135/9781446221013.

Fullan, M. (2001). The new meaning of educational change (3rd ed.). New York: Teachers College Press. https://doi.org/10.4324/9780203986561.

Hallinger, P., \& Leithwood, K. (1996). Culture and educational administration: A case of finding out what you don't know you don't know. Journal of Educational Administration, 34(5), 98-116. https://doi.org/10.1108/09578239610148296.

Harris, A. (2007). Distributed leadership: conceptual confusion and empirical reticence. International Journal of Leadership in Education, 10(3), 315-325. https://doi.org/10.1080/13603120701257313.

Harris, A. (2008). Distributed leadership: according to the evidence. Journal of Educational Administration, 46(2), 172-188. https://doi.org/10.1080/13603120701257313.

Javid, C. Z., Al-thubaiti, T. S., \& Uthman, A. (2012). Effects of English Language Proficiency on the Choice of Language Learning Strategies by Saudi English-major Undergraduates. English Language Teaching, 6(1), 35. https://doi.org/10.5539/elt.v6n1p35.

Jones, S., Lefoe, G., Harvey, M., \& Ryland, K. (2012). Distributed leadership: A collaborative framework for academics, executives and professionals in higher education. Journal of Higher Education Policy and Management, 34(1), 67-78. https://doi.org/10.1080/1360080x.2012.642334.

Leithwood, K. A., Jantzi, D., \& Steinbach, R. (1999). Changing leadership for changing times. Philadelphia: Buckingham.

MacBeath, J. (2009). Distributed leadership paradigms, policy, and paradox. In K. Leithwood, B. Mascall, \& T. Strauss (Eds.), Distributed leadership according to the evidence (pp. 41-57). New York. Routledge. 


\section{Macrothink}

International Journal of English Language Education

ISSN 2325-0887 2021, Vol. 9, No. 2

Morrison, K. (1998). Management theories for educational change. London: P. Chapman Pub. https://doi.org/10.4135/9781446219300.

Prokop, M. (2003). Saudi Arabia: the politics of education. International Affairs, 79(1), 77-89. https://doi.org/10.1111/1468-2346.00296.

Vision 2030. (2021). Human Capability Development Program. https://www.vision2030.gov.sa/v2030/vrps/hcdp/

\section{Copyright Disclaimer}

Copyright for this article is retained by the author(s), with first publication rights granted to the journal.

This is an open-access article distributed under the terms and conditions of the Creative Commons Attribution license (http://creativecommons.org/licenses/by/4.0/). 